\title{
Low Temperature Grafting of MMA on to Coir Fibre
}

\author{
Lakshmi N. S. ${ }^{1}$, Sarika Babu ${ }^{2}$, Sumy Sebastian ${ }^{3}$ and P.K. Ravi ${ }^{4}$
}

\begin{abstract}
Low temperature grafting of methyl methacrylate (MMA) on to coir fibre was carried out in aqueous medium using Potassium per sulphate (PPS) as an initiator under the catalytic influence of Ferrous ammonium sulphate (FAS). Optimization of various parameters of grafting viz. monomer, initiator and catalyst concentration, time and temperature was carried out to obtain the maximum tensile properties. Evidence of grafting was characterized from Fourier Transform Infrared spectroscopy (FTIR), Scanning Electron Microscopy (SEM) and Thermal analysis (TGA). The maximum breaking stress (BS) of control and grafted coir fibre were 213.08 and $365.00 \mathrm{~N} / \mathrm{mm}^{2}$ respectively. Hence the percentage of improvement of grafted coir fibre was found to be $71.30 \%$. Increase in tensile properties with maximum BS observed under monomer $(25 \%)$, initiator $(0.75 \%)$ and catalyst $(0.75 \%)$ concentration, time $(150 \mathrm{~min})$ and temperature $\left(50^{\circ} \mathrm{C}\right)$ respectively. The t-test and Analysis of variance (ANOVA) were studied for statistical significance and the $\mathrm{P}$ values obtained were less than 0.05 which revealed that the value was highly significant for the improvement of mechanical strength on coir fibre by graft Co- polymerization.
\end{abstract}

Keywords: Methyl Methacrylate, Potassium persulphate, Ferrous ammonium sulphate, grafting, Copolymerization.

\footnotetext{
${ }^{1}$ Incubation Assistant, Department of Chemistry, Central Coir Research Institute (Coir Board), Alleppey, Kerala. Email: lakshmins.satheesan@gmail.com

${ }^{2}$ Project Assistant, Department of Chemistry, Central Coir Research Institute (Coir Board), Alleppey, Kerala. Email: sarikababu85@gmail.com

${ }^{3}$ Scientific Assistant, Department of Chemistry, Central Coir Research Institute (Coir Board), Alleppey, Kerala. Email: sumysebastian@yahoo.com

${ }^{4}$ Senior Scientific Officer, Department of Chemistry, Central Coir Research Institute (Coir Board), Alleppey, Kerala. Email: ccrikalavoor@yahoo.co.in
} 


\section{Introduction}

Natural fibers are abundant, versatile, renewable, cheap and biodegradable raw material which can be used for making wide variety of products. Natural fibers have a number of advantages such as low cost, less toxicity, non abrasive nature and easy process ability. Among the natural fibres, Coir occupies a prominent position owing to its qualities such as natural resilience, biodegradability, salt resistance, mechanical strength and toughness which enhances its commercial and industrial usefulness. (Singha and Raj, 2010)

Coir is a multicellular biopolymer in which crystalline cellulose is arranged helically in a matrix consisting of non crystalline lignocellulosic complex. (Ott et. al., 1954). Due to hydrophilic nature and low thermal stability coir fibers have got certain limitations. There are several methods such as acetylation, benzoylation, grafting, silane treatment, plasma treatment etc. which have been employed to improve the properties of the natural fibers through surface modification. Graft copolymers are assuming increasing importance because of their tremendous industrial potential. Graft copolymerization is one of the best techniques for modifying the properties of natural polymers. It is a convenient and clean means for altering the properties of numerous polymer backbones. As the natural fibres bear hydroxyl groups from cellulose and lignin, they are amendable to chemical modifications. Chemical modification may activate these groups or can introduce new moieties that can effectively interlock with matrix. Modifying the properties of natural polymers through graft copolymerization has been reported by various workers. (Renu et. al., 2010). Desirable and targeted properties can be imparted to the natural polymers through graft copolymerization in order to meet out the requirement of specialized applications. Grafted fibers have been found to increase the strength and thermal stability than raw fibers.

In the present study coir fibre was grafted with Methyl Methacrylate (MMA) for improving its properties such as tensile strength, thermal stability, light fastness and resistance to chemicals. In order to make modification process more economic, effort has been made to find out the optimum modification condition depending on the concentration of monomer, initiator and catalyst, reaction time and temperature. Graft yield was determined on the basis of the weight increase of the coir fibre treated. Some instrumental analysis such as Infrared spectroscopy (IR), Scanning Electron Microscopy (SEM) and Thermo Gravimetric Analysis (TGA) were done to identify graft on coir fibre.

\section{Materials and methods}

\section{Materials}

Mechanically extracted coir fibres were collected from Alleppey, Kerala. Monomer: Methyl Methacrylate (MMA), Initiator: Potassium per sulphate (PPS) and Catalyst: Ferrous ammonium sulphate (FAS) used was of analytical grade.

\section{Methods}

\section{Purification of materials}

The fibres were cleaned first in Willowing machine and sorted using combing board. The fibres were soaked in water over night. Then it was washed with water under stirring for $8 \mathrm{hrs}$ and dried in hot air oven at 700C.

MMA was washed with $5 \% \mathrm{NaOH}$ solution followed by water and dried over anhydrous sodium sulphate. Catalyst ferrous ammonium sulphate was recrystalised from hot water. Initiator potassium per sulphate was used as received.

\section{Graft Co-polymerization}

Fibres were immersed in distilled water for $24 \mathrm{hrs}$ prior to the reaction. The material to liquor ratio was maintained at 1:50. A known amount of the initiator, catalyst and monomer were then added to the reaction vessel maintained at required temperature. Grafting of MMA on to coir fibre was carried out under constant stirring. At the end of the desired reaction period, the coir fibre was thoroughly washed with acetone to remove any homopolymer generated during the reaction. 
Fibres were then washed with distilled water and dried in a hot air oven at $70^{\circ} \mathrm{C}$ till a constant weight was obtained. Polymerization reaction were done at varying conditions of $5-75 \%$ monomer, $0.0-1.5 \%$ initiator, $0.0-1.25 \%$ catalyst based on the weight of the fibre, $30^{\circ} \mathrm{C}-80^{\circ} \mathrm{C}$ of temperature and 30-210 minute reaction time on to the coir fibre. The reaction conditions were optimized so as to get maximum Grafting Yield (GY) and BS. Percentage GY was calculated by the equation

$$
\mathrm{GY}=\left(\mathrm{W}_{2}-\mathrm{W}_{1} / \mathrm{W}_{1}\right) 100
$$

Where $\mathrm{W}_{1}$ and $\mathrm{W}_{2}$ are the weights of coir fibre and grafted fibre respectively.

\section{Scanning Electron Microscopy (SEM)}

Scanning Electron Microscopy studies of ungrafted coir fibre and grafted coir fibre was carried out on Scanning Electron Microscope (SEM) (JEOL JSM-6390 LV, Tokyo, Japan) system with an accelerating voltage of $10 \mathrm{kV}$. The SEM images are studied under $10 \mu \mathrm{m}$ magnification.

\section{Infrared Spectroscopy (IR)}

Infrared spectra of the ungrafted and grafted coir fibre were taken on Perkin Elemer Spectrophotometer.

\section{Thermo Gravimetric Analysis (TGA)}

The Thermo Gravimetric Analysis (TGA) of the coir fibre was done using Mettler Toledo TGA/SDTA $851^{\mathrm{e}}$, Japan. The test was carried out in an inert atmosphere under nitrogen flow rate at $10 \mathrm{ml} / \mathrm{min}$ and heating rate throughout the test was $10^{\circ} \mathrm{C} / \mathrm{min}$. The weight change was recorded as a function of the heating temperature.

\section{Tensile properties}

Tensile properties of coir fibres were determined using UTM (Universal Testing Machine) Shimadzu AG-X/R. At test parameters; strain rate $=10 \mathrm{~mm} / \mathrm{min}$, gripping length $=5 \mathrm{~cm}$ at atmospheric temperature.

\section{Results and discussion}

\section{Mechanism}

It has been observed that $\mathrm{C}_{2}, \mathrm{C}_{3}, \mathrm{C}_{6}$ hydroxyls and $\mathrm{C}-\mathrm{H}$ sites of cellulose back bone are the active sites of coir fibre for grafting of MMA. PPS takes part in the redox reaction with $\mathrm{Fe}^{2+}$ to produce $\mathrm{SO}_{4}^{-*}$.

$\mathrm{Fe}^{2+}+{ }^{-} \mathrm{O}_{3} \mathrm{~S}-\mathrm{O}-\mathrm{O}-\mathrm{SO}_{3} \longrightarrow \mathrm{Fe}^{3+}+\mathrm{SO}_{4}{ }^{2-}+\mathrm{SO}_{4}{ }^{-*}$

Interaction of $\mathrm{SO}_{4}{ }^{*}$ with $\mathrm{H}_{2} \mathrm{O}$ generates $\mathrm{OH}$ free radicals $\left(\mathrm{OH}^{*}\right)$ and these free radicals are responsible for free radical generation on coir and the monomer as well as further chain propagation there by resulting in the formation of graft copolymer.

Optimization of different reaction parameters for grafting Methyl Methacrylate on to Coir Fibre

Optimization of various reaction parameters such as concentration of the monomer, initiator, catalyst, reaction time and temperature were carried out for graft copolymerization of methyl methacrylate on to coir fibre.

\section{i. Effect of monomer concentration}

Grafting increases with increase in monomer concentration up to $25 \%$ and further increase in monomer concentration results in decrease of grafting yield (fig 1). This may be due to the formation of more homo polymer as compared to graft co-polymer at higher monomer concentration. Due to homo polymerization, viscosity of the reaction medium increases which creates hindrance in the movement of the free radical towards the active sides, there by resulting in decrease of grafting yield (Singha et.al., 2007 ).

\section{ii. Effect of initiator}

The initiator plays an important role in obtaining higher graft yield. It is observed (fig 2) that the percentage of grafting increases with increase in initiator concentration PPS up to $0.75 \%$ and there after the percentage of grafting starts decreasing. 


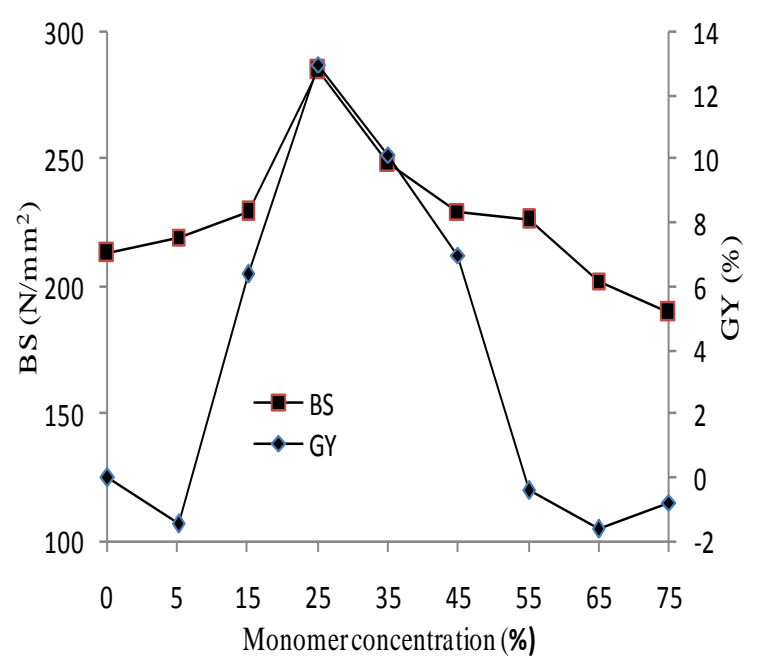

Figure 1.

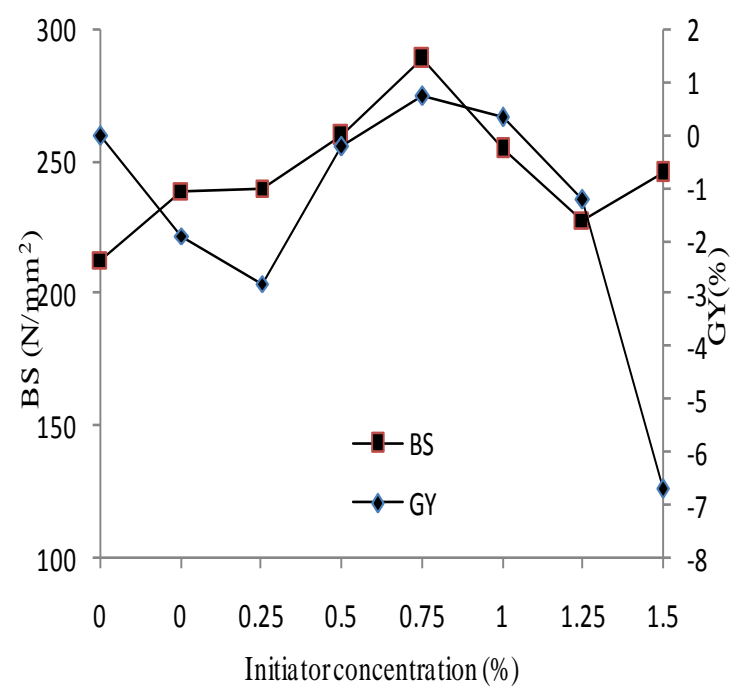

Figure 2.

Initiator PPS generates activated monomers, which show a sufficient affinity to cellulose macro radicals that are produced by the action of catalyst FAS on the surface of coir fibre and enhances the grafting up to a certain initiator concentration (Arifuzzaman Khan et. $a l ., 2009)$. But at a high initiator concentration large number of activated monomers accumulates and forms the homo polymer, thereby reducing the active monomers available in the vicinity of cellulose macro radicals and hence the percentage of grafting starts decreasing. Decrease in grafting may also be explained due to the termination of growing grafted chain by primary free radical resulting from the decomposition of excess initiator.

\section{iii. Effect of catalyst}

It is observed that (fig 3) grafting yield increased with increasing catalyst concentration. As the catalyst concentration increases, more numbers of $\mathrm{Fe}$ (III) ions as well as more reactive site on the coir fibre surface are produced, thereby increasing the grafting up to a certain concentration of catalyst. But beyond this concentration the grafting yield declined. This is probably due to the formation of large number of $\mathrm{Fe}$ (III) ions which promote the premature termination of the growing grafted chain.

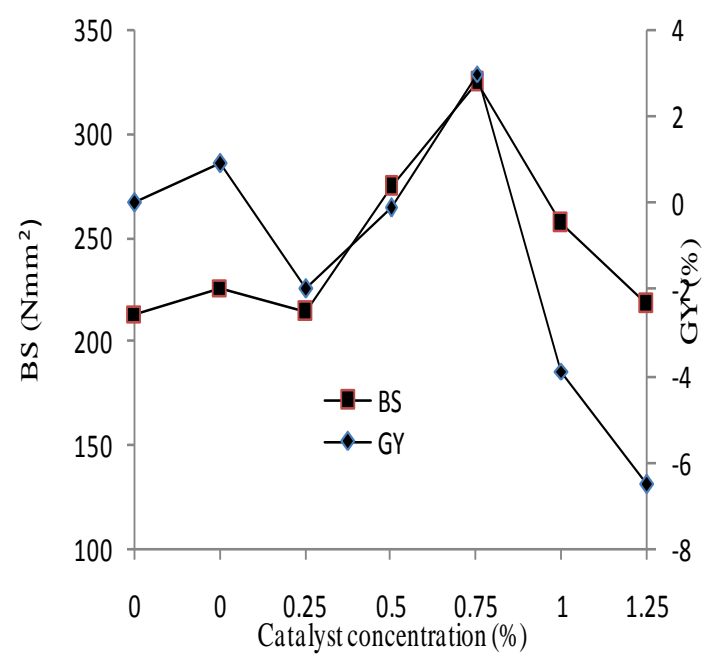

Figure 3.

\section{iv. Effect of reaction time}

The percentage of grafting increases with increase in reaction time up to $150 \mathrm{~min}$ for MMA and there after the percentage of grafting starts decreasing (fig 4). The initial sharp increase in grafting is due to the high co-polymerization reaction between the reactive sites of coir fibre and the activated monomer molecules. After $150 \mathrm{~min}$ the homo polymerization reaction prevails over the co polymerization possibly due to the decrease in reactive sites on the coir fibre (Salam, M.A. 2005). So the percentage of grafting becomes steady. On prolonged exposure 
to heat, the percentage of grafting decreases due to the partial dissolution of grafted fibre.

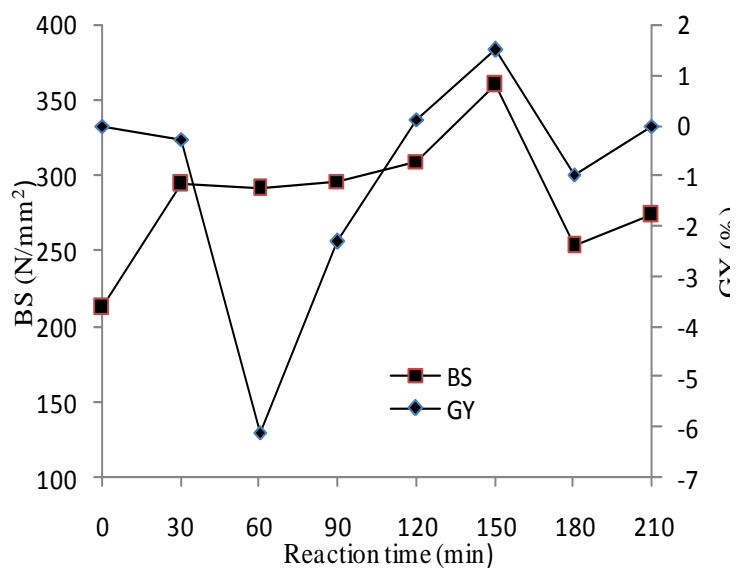

Figure 4.

\section{v. Effect of temperature}

It is observed that at ordinary temperature, the grafting is slow. But at $50^{\circ} \mathrm{C}$ the percentage of grafting is high (fig 5). The increasing percentage of grafting up to optimum temperature may be due to increase in the rate of production of active free radical which increase the number of grafting sites at a higher rate, the rate of initiation by coir fibre radicals is thereby increased. The increase in temperature increases the rate of diffusion of monomers into the coir fibre matrix. The decrease in percentage of grafting beyond optimum temperature may be attributed to the increase in the rate of homo polymerization.

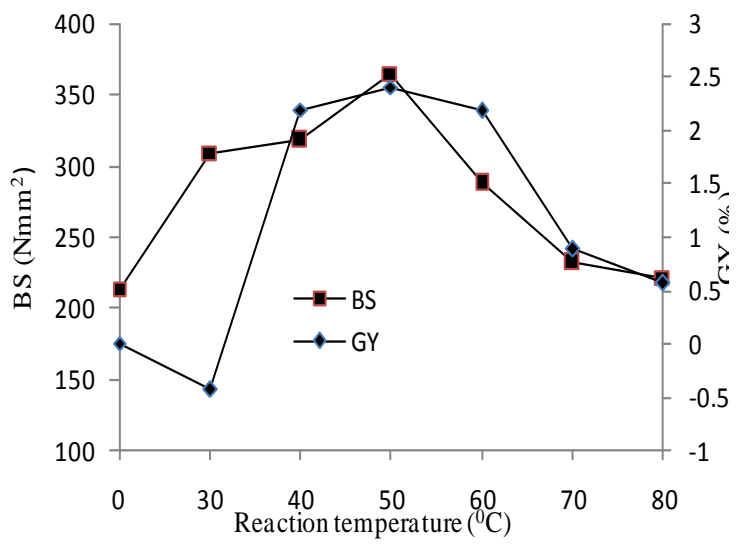

Figure 5.
The t-test was studied for statistical significance and all the $\mathrm{P}$ values obtained were less than 0.05 (table). Since it shows that the values were statistically significant. Analysis of variance (ANOVA) of BS of grafted Coir fibre $(\mathrm{P}<0.0021)$ was also calculated and the $\mathrm{p}$ value is $(p<0.05)$ revealed that this was highly significant for the improvement of mechanical strength on Coir fibre by graft Co-polymerization.

\section{Characterisation Study}

\section{Scanning Electron Microscopy (SEM)}

It is quite evident from figures that there has been a sufficient deposition of MMA on to coir fibre. Comparison of the Scanning electron micrographs of ungrafted coir fibre Fig. 6(a) and MMA grafted coir fibre; Fig. 6(b) reveals a clear cut distinction between the ungrafted and grafted fibers.

Figure 6. SEM images of (a) Ungrafted Coir fibre (b) MMA grafted Coir fibre

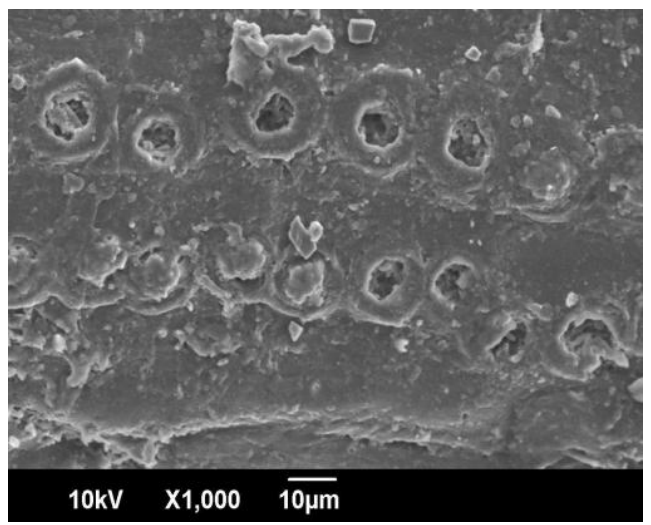

Figure 6(a)

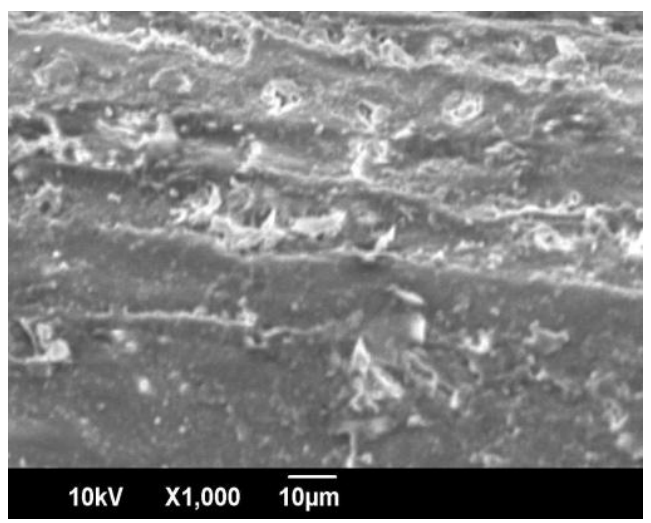

Figure 6(b) 
The pits observed in ungrafted coir fibre are no longer observed in grafted fibres. The surface becomes more or less uniform owing to deposition of PMMA grafts along the direction of fibre axis. This orderly arrangement of PMMA changes the porous surface of coir fibre resulted in an appreciable increase in the strength of grafted fibres compared with ungrafted fibres (Khullar et. al., 2008).

\section{FTIR Spectra}

Figure 7. FTIR spectrums of the (a) ungrafted coir and (b) MMA grafted Coir fibre

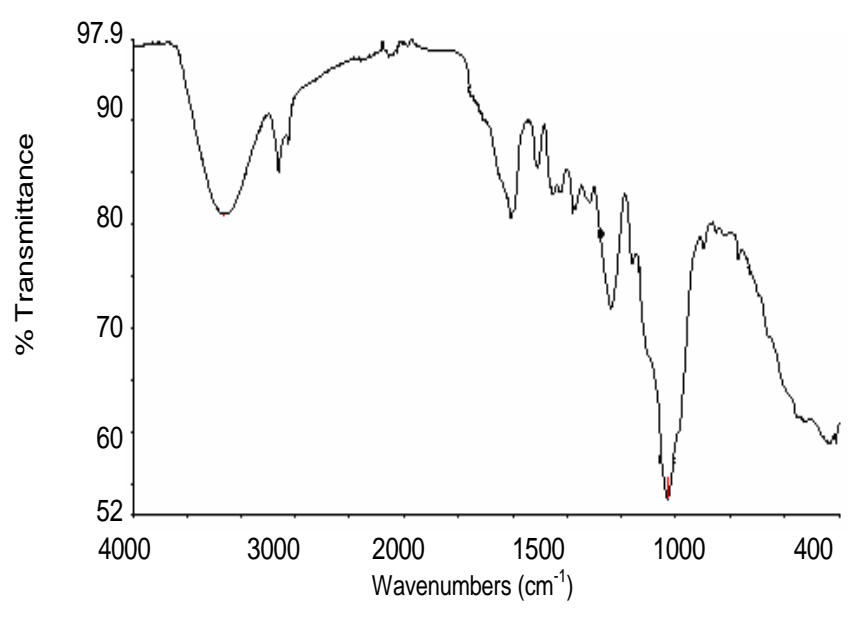

Figure 7(a)

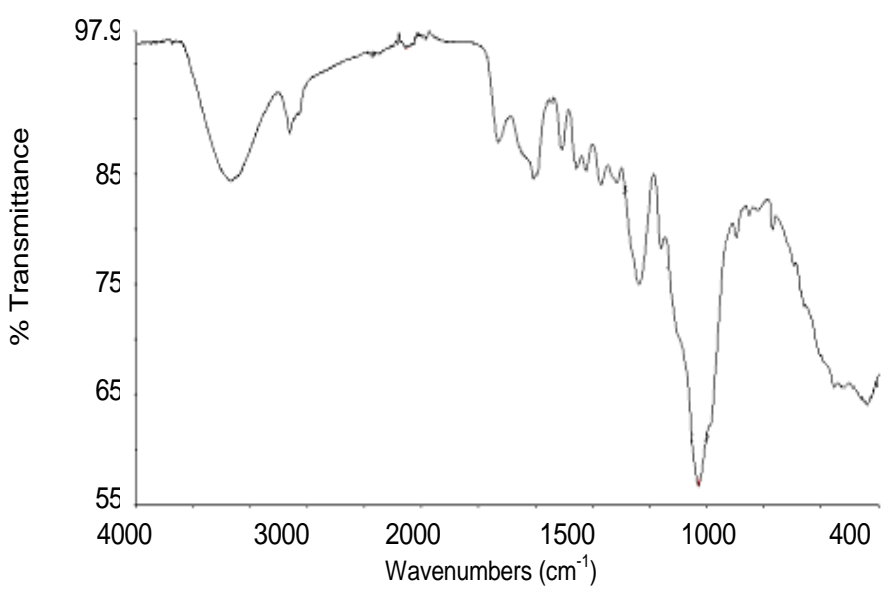

Figure 7(b)
The peak assignments of the absorption band corresponding to various groups are summarized in table 1 (Zuraida et. al., 2011)

Table 1. FTIR spectral data of ungrafted Coir fibre

\begin{tabular}{|c|c|}
\hline Position / cm & Possible Assignment \\
\hline$\sim 3600-3200$ & $\begin{array}{l}v(\mathrm{OH}) \text { broad, strong band from } \\
\text { the cellulose, hemicellulose and } \\
\text { lignin of coir }\end{array}$ \\
\hline$\sim 3000-2900$ & $\begin{array}{l}v(\mathrm{C}-\mathrm{H}) \text { in aromatic rings and } \\
\text { alkanes }\end{array}$ \\
\hline$\sim 1732.7$ & $\begin{array}{l}v(\mathrm{C}=\mathrm{O}) \text { most probably from the } \\
\text { lignin and hemicelluloses }\end{array}$ \\
\hline$\sim 1608.5$ & $v(\mathrm{C}=\mathrm{C})$ aromatic in-plane \\
\hline$\sim 1512.6$ & $\begin{array}{l}v(\mathrm{C}=\mathrm{C}) \text { aromatic skeletal ring } \\
\text { vibration due to lignin }\end{array}$ \\
\hline$\sim 146$ & $\begin{array}{l}\delta(\mathrm{C}-\mathrm{H}) ; \quad \delta \quad(\mathrm{C}-\mathrm{OH}) \quad 10 \quad \& \quad 20 \\
\text { alcohol }\end{array}$ \\
\hline$\sim 1426.6$ & $\delta(\mathrm{C}-\mathrm{H})$ \\
\hline$\sim 1375.4$ & $\delta(\mathrm{C}-\mathrm{H})$ \\
\hline$\sim 1267.4$ & $\delta(\mathrm{C}-\mathrm{OH})$ out-of-plane \\
\hline$\sim 1046.0$ & $v(\mathrm{C}-\mathrm{OH}) 20$ alcohol \\
\hline$\sim 898.5$ & $v(\mathrm{C}-\mathrm{O}-\mathrm{C})$ in plane symmetric \\
\hline
\end{tabular}

FTIR spectrum of ungrafted coir and MMA grafted coir fibre are shown in fig.7 (a-b). The ungrafted coir fiber shows the characteristic absorption of $-\mathrm{OH}$ group $\sim 3600-3200 \mathrm{~cm}^{-1}$ (Zuraida et. al., 2011). But in MMA grafted coir fibre, broadening of absorption band takes place at $\sim 3600-3200 \mathrm{~cm}^{-1}$. The intensity of $-\mathrm{OH}$ peaks in MMA grafted fibres reduced as a result of grafting, since it is the probable site of grafting. Grafted fibre shows an additional peak at $\sim 1732 \mathrm{~cm}-1$ may be due to the presence of $(\mathrm{C}=\mathrm{O})$ of MMA.( Balamurugan et. al., 2004; Jogeswari et. al., 1999a).

\section{Thermo gravimetric analysis (TGA)}

Thermal behavior of ungrafted coir fibre and its MMA grafted coir fibre were examined by a study of their TGA thermograms. From the results, listed in Table 2, it is evident that initial and final decomposition temperature of ungrafted coir fibre are 80 and $450^{\circ} \mathrm{C}$ where as in the case of MMA grafted coir fibre the initial and final decomposition temperature are $90^{\circ} \mathrm{C}$ and $670^{\circ} \mathrm{C}$ respectively (Fig. $8(\mathrm{a} \& \mathrm{~b}$ ). From the 
results it is observed that the thermal stability of MMA- grafted fibre is higher than that of ungrafted fibre. (Jayaraj et. al., 2014)

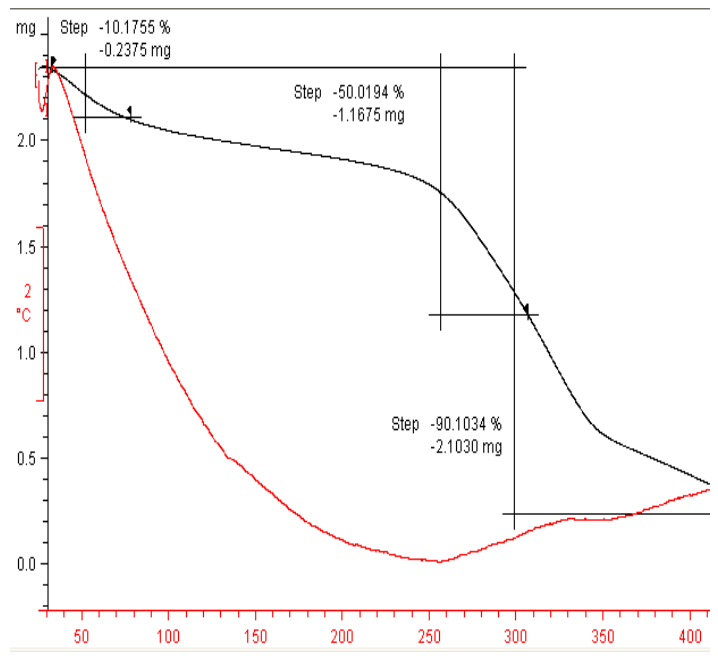

Figure 8(a)

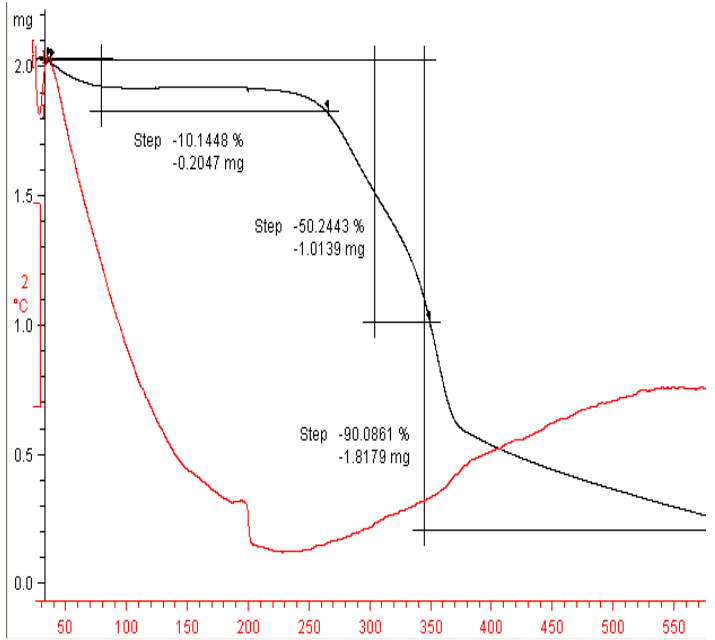

Figure 8(b)

Table 2. TGA of ungrafted and MMA grafted Coir fibre

\begin{tabular}{|llll|}
\hline Sample & $\begin{array}{l}\mathrm{T} 10 \\
\left({ }^{\circ} \mathrm{C}\right)\end{array}$ & $\begin{array}{l}\text { T50 } \\
\left({ }^{\circ} \mathrm{C}\right)\end{array}$ & $\begin{array}{l}\mathrm{T} 90 \\
\left({ }^{\circ} \mathrm{C}\right)\end{array}$ \\
\hline Untreated coir fibre & 80 & 310 & 450 \\
$\begin{array}{l}\text { MMA grafted coir } \\
\text { fibre }\end{array}$ & 270 & 350 & 630 \\
\hline
\end{tabular}

\section{Tensile Properties}

The tensile properties of ungrafted and grafted coir fibre were determined by taking a minimum of 50 fibres from each optimization fig. 1 to 5 .

It clearly shows that there is an appreciable change in the tensile properties under maximum stress at break. Grafting of coir fibres with MMA from control to complete optimization brings about a substantial increase in maximum stress at break. The increase in maximum stress in the case of completely optimized fibre from 213.08 $\mathrm{N} / \mathrm{mm}^{2}$ to $365 \mathrm{~N} / \mathrm{mm}^{2}$ may be due to the increase in the degree of crystallinity due to the orderly arrangement of the short grafts of the PMMA units on the cellulosic backbone. In all the cases of grafting it has been found that the maximum stress at break is higher than ungrafted fibre Fig. 9 (a). (Jogeswari et. al., 1999b)

Figure 9. Tensile properties of Optimized Condition

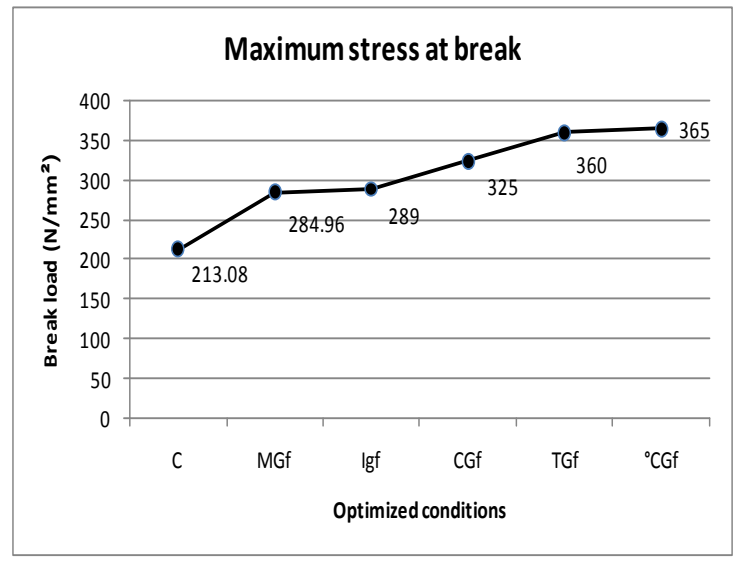

Figure 9(a)

\section{Conclusion}

Low temperature Graft Copolymerization of MMA on to coir fibre was done at an optimum temperature of $50^{\circ} \mathrm{C}$. Percent of grafting increases with the increase in each of the reaction parameters, such as monomer concentrations, initiator concentrations, catalyst concentrations, polymerization time and temperature up to a limited extent and then decreases. During graft copolymerization 
keeping all other variables constant, better graft yield were obtained at $50^{\circ} \mathrm{C}, 2.30 \mathrm{hr}, 25 \%$ monomer, $0.75 \%$ initiator, $0.75 \%$ catalyst. The polymer grafted on to coir fibre improves magnificently the tensile strength. FTIR, SEM and TGA measurements characterized the extent of grafting.

\section{Acknowledgments}

The authors are very much grateful to Coir Board, Cochin and Central Coir Research Institute (CCRI), Kalavoor for permitting to conduct the studies and publication of this article.

\section{References}

Arifuzzaman Khan, G.M., Sheruzzaman., S.M. Abdur Razzaque., Sakinul Islam and Shamsul Alam. 2009. Grafting of acrylonitrile monomer on to bleached okra bast fibre and its textile properties. Indian J. Fibre and Textile Research 34: 321-327.

Balamurugan, A., Kannan, S., Selvaraj, V. and Rajeswari, S. 2004. Development and Spectral Characterization of Poly (Methyl Methacrylate) /Hydroxyapatite Composite for Biomedical Applications. Trends Biomater. Artif. Organs, Vol. 18 (1), 4145.

Jayaraj A.P., Anitha Das Ravindranath and U.S. Sarma. 2014. Nanocellulose from diseased coconut wood. Cord 30 (1), 1-10.

Jogeswari R., Manjusri M. and Amar K.M. 1999. Surface Modification of Coir Fibers I: Studies on Graft Copolymerization of Methyl Methacrylate on to Chemically Modified Coir Fibers. Polym. Adv. Technol. 10: 336-344.

Kaith, V.S and S. Kalia. 2008. Graft Copolymerization of MMA on to flax under different reaction conditions: a comparative study. eXPRESS Polymer Letters 2(2): 93-100.

Khullar, R., V.K. Varshney., S. Naithani and P.L. Soni. 2008. Grafting of acrylonitrile on to cellulosic material derived from bamboo (Dendrocalamus strictus). eXPRESS Polymer Letters 2 (1): 12-18.

Ott E, Spurline H M \& Graffin M W, 1954. Cellulose and cellulose derivatives, Part II (Interscience, Newyork), 863

Renu S., S Vashistha and S. Kalia. 2010. Biologically and chemically modification of ramie fibers: A comparative study. International Conference on Advance in polymer Technology.239

Salam, M.A. 2005. Graft co polymerization of methyl acrylonitrile monomer on to sulfonated jute- cotton blended fabric. J. Textile and Apparel technology and Management 4(4).

Singha, A.S., S. Anjali and V.K. Thakur. 2007. Pressure induced graft copolymerization of acrylonitrile on to Saccharum cilliare fibre and evaluation of some properties of grafted fibre. Bull. Master. Sci. 31(1):713.

Singha A.S and Raj K.R. 2010. Graft Copolymerization of Methyl Methacrylate (MMA) onto Agave americana Fibers and Evaluation of their Physicochemical Properties. International Journal of Polymer Analysis and Characterization 11(1):27-42.

Zuraida, A., S. Norshahida., Sopyan and H. Zahurin. 2011. Effect of fibre length variation on mechanical and physical properties of coir fibre reinforced cementalbumin composite (CFRCC). J. IIUM Engineering 12(1). 